Human and Ecological Risk Assessment: An International Journal, Volume 19, Issue 4, 2013, Pages 1038-1048

\title{
Impact Assessment of an Independent Agency for Animal Health in England
}

\author{
A.M. Gormley, ${ }^{1}$ E.L. Snary, ${ }^{2}$ S.A. Rocks, ${ }^{1}$ and S.J.T. Pollard ${ }^{1}$ \\ ${ }^{1}$ Cranfield University, Collaborative Centre of Excellence in Understanding and Managing \\ Natural and Environmental Risks, School of Applied Sciences, Cranfield, Bedfordshire, UK; \\ ${ }^{2}$ Animal Health and Veterinary Laboratories Agency, Centre for Epidemiology and Risk \\ Analysis, New Haw, Addlestone, Surrey, UK \\ Address correspondence to AM Gormley. Cranfield University, Collaborative Centre of \\ Excellence in Understanding and Managing Natural and Environmental Risks, Cranfield, \\ Bedfordshire, UK, MK43 0AL; Tel: +44(0)1234 750111. E-mail: agormley@ rsk.co.uk
}

Running Head: Estimating Costs and Benefits for a New Animal Health Agency

Received 2 September 2011; revised manuscript accepted 24 May 2012 


\begin{abstract}
The applicability of a stochastic model was explored to assess the impact of a new independent agency for animal health in England in terms of the cost of animal disease outbreaks. The new agency was proposed to take responsibility for animal disease management in England. The stochastic model estimates the likelihood that the proposed new agency would face animal disease outbreaks of major and minor magnitude; and how many outbreaks of each magnitude, within its first 30 years of operation. Large variability in the potential total cost of the new agency was attributable to the possibility of an outbreak of an unknown major disease, although Bluetongue, Foot and Mouth Disease, and Avian Influenza were also influential. The results show that if the new agency reduces disease costs by even $0.5 \%$, this could benefit society by an estimated $£ 21$ million per year. The stochastic approach offers a method for dealing with uncertainties in any continuing deliberations regarding the proposed new agency, resulting in a potential annual gain of $£ 73$ million ranging to an annual loss of $£ 144$ million.
\end{abstract}

Key Words: animal disease; risk assessment; environmental policy; impact assessment, stochastic approaches. 


\section{INTRODUCTION}

Outbreaks of animal diseases have enormous economic, social, and environmental consequences to the UK national economy (Anderson 2002, 2008). Mitigating these requires a comprehensive and informed risk management scheme. Currently in the UK, the responsibility for animal disease management lies with the Department for Environment, Food and Rural Affairs (Defra). This responsibility was proposed to transfer to a new independent agency for animal health in England by 2012, although Defra ministers would retain overall responsibility for animal disease policy (Defra 2009a). The proposed new agency (herein, 'the new agency') was part of the Government's drive to achieve efficiency in animal disease management in England. To assess the investment potential of the new agency, Defra (2009b) relied on expert opinion about disease risks based on the return periods (RP) of Avian Influenza, Bluetongue, Newcastle Disease, Classical Swine Fever, Foot and Mouth Disease, African Swine Fever, and Swine Vesicular Disease. The RP is the mean length of time between outbreaks that have equalled or exceeded a certain magnitude. The reciprocal of the RP is a probability estimate of the event occurring in any given year (Ozger and Sen 2008).

Return periods are widely used to reflect the magnitude of flood events, but a limitation of using the RP of diseases to assess the risk of future animal disease outbreaks is that the RP does not account for variations in the distribution of what are often rare outbreaks involving highly complex chains of precursor events (Gosling et al. 2011). For example, as the new agency has been proposed to exist for 30 years (Defra 2009b), a disease with an RP of 60 years may or may not occur during the lifespan of the new agency. This can affect the rationale for the new agency. Here, we use a stochastic model to build on the RP of the diseases (Defra 2009b) in order to assess the impact of the new agency. The stochastic model was developed to estimate the likelihood that the new agency would face disease outbreaks of both major and minor magnitude; and more importantly, how many outbreaks of each magnitude, within its first 30 years of operation. It uses the estimated costs of disease outbreaks and the running costs of the new agency to present the possible benefits of the new agency under four hypothetical scenarios.

\section{METHODS}

A stochastic model was developed to estimate the number of animal disease outbreaks that may occur within the 30-year lifespan of the new agency. Adopting a stochastic approach 
allowed the incorporation of variability (Ranjan and Lubowski 2005), and provided additional information to the expected number of outbreaks, e.g., $5^{\text {th }}$ and $95^{\text {th }}$ percentiles.

To make decisions covering the lifespan (30 years) of the new agency, the number of minor and major outbreaks of animal disease were estimated. The distinction between major and minor outbreaks is a simplistic representation of disease outbreaks that encompasses the average costs for minor disease outbreaks controlled at low cost, and much rarer years of one (or even more) major high cost disease outbreak(s). These range from small (one animal or premises affected, with minimal trade disruption) to nationwide (thousands of affected premises, very high eradication costs, and long disruption to businesses) (Defra 2009b). This enabled an estimation of the total cost of outbreaks to which set-up and running costs of the new agency could be added. Data available from Defra (2009b) provided information on the likely frequency (i.e., an outbreak once every "how many" years) of an exotic disease outbreak for different diseases (Table 1). Using these data, the analysis focused on nine diseases, i.e., Avian Influenza (AI), Bluetongue (BT), Newcastle Disease (ND), Classical Swine Fever (CSF), Foot and Mouth Disease (FMD), African Swine Fever (ASF), and Swine Vesicular Disease (SVD). It is important to emphasise that the probabilities and costs provided by Defra reflect expert opinion about disease risks based on the information available. The data used by the Government's expert elicitation panel dates back to year 1866 (Defra 2009b). The figures are not intended to be forecasts nor predictions of what will happen; rather to illustrate the possible scale of outbreak costs in a year to show what might be achieved by reducing those costs.

The stochastic model was developed using the @ $\operatorname{Risk}^{\mathrm{TM}}$ (v5.5, Palisade Corporation) add-on to Microsoft Excel (Charles and Ashbolt 2004). To estimate the number of outbreaks of disease $i(i=1, \ldots, 9)$ within a 30-year period $\left(O_{i}\right)$ a Poisson distribution was used (Vose 2008), which assumes that each outbreak is independent of each other (IRMA 2003; Williams et al. 2009; Willeberg et al 2011). This is given as

$$
O_{i}=\text { RiskPoisson }\left(\frac{30}{y_{i}}\right)
$$

where $y_{i}$ is the estimated number of years between outbreaks of disease $i$, which is given from Table 1.

The cost of the disease outbreak is dependent on whether the outbreak is major or minor. The probability of a minor outbreak of disease $i\left(P_{i, \text { Minor }}\right)$ and the probability of a major outbreak 
of disease $i\left(P_{i, \text { Major }}\right)$ were also taken from Defra $(2009 \mathrm{~b})$ and are detailed in Table 1. Using the probability $P_{i, \text { Minor }}$, the number of minor outbreaks $\left(O_{i, \text { Minor }}\right)$ was determined by a Binomial distribution:

$$
O_{i, \text { Minor }}=\operatorname{RiskBinomial}\left(O_{i}, P_{i, \text { Minor }}\right)
$$

and therefore, the number of major outbreaks $\left(O_{i, M a j o r}\right)$ was given by subtracting the number of minor outbreaks from the total number of outbreaks, i.e., $O_{i, \text { Major }}=O_{i}-O_{i, \text { Minor }}$.

The $\operatorname{cost} C_{i}$ of outbreaks of animal disease $i$ in the 30-year period was therefore calculated as:

$$
C_{i}= \begin{cases}O_{i, \text { Major }} c_{i, \text { Major }} & \text { if } i=8 \\ O_{i, \text { Minor }} c_{i, \text { Minor }}+O_{i, \text { Major }} c_{i, \text { Major }} & \text { if } i \neq 8\end{cases}
$$

where $c_{i, \text { Minor }}$ is the incident cost in millions (£M) if outbreak of disease $i$ is minor and $c_{i, \text { Major }}$ is the incident cost (£M) if outbreak of disease $i$ is major.

The $y_{i}$ and $c_{i, m a j o r}$ of "unknown major disease" were determined by Defra (2009b) based on their historical data of outbreaks that are, for example, similar in scale to the BSE outbreak in the UK during the 1980s/early 1990s, and have been in the past highly unlikely event (1\% risk in any year) but if it should arise it would cause very high costs (e.g., $£ 5$ billion - similar in scale to BSE). The very high cost of such an event leads to the high "expected annual cost".

For the purpose of undertaking a cost-benefit analysis of the proposed new agency, the estimated set-up and annual running cost of the new agency were taken from Defra (2009b), i.e., $£ 14.3$ million and $£ 2.7$ million, respectively. Therefore, the total cost, C, (£M) of set-up and running the new animal health agency and of outbreaks in the 30-year period under consideration was determined in this paper as:

$$
C=\sum_{i=1}^{9} C_{i}+14.3+(30 * 2.7)
$$

These data were used in the following four scenarios (A-D) to estimate the total financial benefit of the new agency. The percentage cost reductions were arbitrarily determined and initially set out by Defra (2009b).

- Scenario A: Design and establishment of the new agency would result in $0.5 \%$ (noncompounding) reduction outbreak cost over a 30-year period.

- Scenario B: Design and establishment of the new agency would result in $2 \%$ (noncompounding) reduction in outbreak cost over a 30-year period. 
- Scenario C: Design and establishment of the new agency would result in $10 \%$ (noncompounding) reduction in outbreak cost over a 30-year period.

- Scenario D: Design and establishment of the new agency would result in $0.5 \%, 2 \%$ and $10 \%$ (non-compounding) reduction in outbreak cost each year for years 1-10, 11-20, and 21-30, respectively.

For Scenarios $\mathrm{A}-\mathrm{C}$ in the scenario analysis, the costs of each outbreak were reduced accordingly. Within Scenario D, the number of (major and minor) outbreaks within each 10-year period was estimated and outbreak costs (with associated reductions $0.5 \%, 2 \%, 10 \%$ ) applied to each period. The costs of outbreaks in the 30-year period were subsequently calculated by adding together the costs from the three periods considered, in addition to the set-up and running costs.

In addition to the above scenario analysis, the impact of the new agency having an increased probability of an outbreak being minor $\left(P_{i, \text { minor }}\right)$ was investigated for each disease on the total cost of the disease outbreaks (under the baseline scenario, i.e., without any additional financial benefits).

The Monte Carlo simulation model was executed using @Risk ${ }^{\mathrm{TM}}$, with latin hypercube sampling, and run for 100,000 iterations. This number of iterations was sufficient to ensure convergence for the means of the number of minor and major outbreaks within a $95 \%$ confidence level (3\% tolerance), which are the default settings in @ Risk ${ }^{\mathrm{TM}}$. Sensitivity analyses were undertaken using @ Risk ${ }^{\mathrm{TM}}$ (Vose 2008) in order to ascertain the relative importance of all variables to the cost of animal disease outbreak for the baseline model.

\section{RESULTS}

Based on the simulated probabilities of a minor outbreak of disease $i$ ( $\left(P_{i, \text { Minor }}\right)$, the estimated number of minor outbreaks $\left(O_{i, \text { Minor }}\right)$ over a 30 -year period is shown in Figure 1. This shows, for example, the number of minor outbreaks of ND was estimated to have a mean value of 9.5 ( $5^{\text {th }}$ percentile $5 ; 95^{\text {th }}$ percentile 15). Likewise, provided in Figure 2 is an estimate for the number of major outbreaks $\left(O_{i, \text { Major }}\right)$ over 30 years based on the simulated probabilities of a major outbreak of disease $i\left(P_{i, \text { Major }}\right)$. From Figure 1, AI has a substantially higher number of minor outbreaks in a 30 -year period $(54(42,66))$ compared to the other animal diseases. The $90^{\text {th }}$ percentile range $(2,10)$ for major outbreaks of AI overlaps with other diseases, e.g., BT, 
CSF, OKN (Figure 2). Therefore the number of major AI outbreaks is more similar to the other animal diseases considered.

The estimated costs (£M) due to minor and major animal disease outbreaks in 30 years $\left(C_{i}\right)$ are shown in Figure 3. Although it is predicted that the largest number of outbreaks will be from AI, it is the costs associated with an outbreak of an UMD that are the highest. In addition, the variability about the cost is wide with the $95^{\text {th }}$ percentile at $£ 5000$ million. This is because, although the probability of having such an outbreak is low (1 in every 100 years), the cost of such an outbreak was estimated to the $£ 5000$ million. BT outbreaks would also be costly to the new organisation, but the situation is slightly different here because the probability of an outbreak is high (once in every 2 years) and the cost is also relatively high. The costs of an AI outbreak are relatively low, and therefore although a high number of outbreaks may occur, overall, this disease would not contribute most to the cost of managing disease outbreaks. The other diseases have a much lesser impact on the estimated mean cost of outbreak management over a 30-year period.

Based on the total mean cost per outbreak of the diseases and the likelihood that the disease outbreaks will occur over the 30-year period, total disease outbreaks (i.e., across all diseases) could potentially cost $£ 4118$ million $(1925,8440)$. The large degree of variability associated with this overall estimate (as seen from the 5 th and $95^{\text {th }}$ percentiles) is attributable to the variability associated with an outbreak of an UMD, as discussed above.

From the scenario analysis (A-D) the costs of outbreak based on the estimated savings from setting up the new agency are compared in Figure 4. This shows, for example, if the new agency achieved a reduction of $2 \%$ in the cost of animal disease outbreaks over 30 years (Scenario B), and with the expected cost of disease outbreaks over this time totalling $£ 4118$ million $(1925,8440)$ and the estimated set-up and annual running cost of the new agency ( $£ 14.3$ million and $£ 2.7$ million, respectively), this would benefit $£ 80$ million. Likewise, if the new agency achieved a reduction of $0.5 \%, 2 \%$, and $10 \%$ in the cost of animal disease outbreaks each year for years $1-10,11-20$, and $21-30$, respectively (Scenario D), this would benefit $£ 167$ million after the set-up and annual running costs of the new agency are accounted for. Even at the minimal benefit of the new agency achieving a reduction of $0.5 \%$ in the cost of animal disease outbreak over 30 years (Scenario A), and with the set-up and annual running costs of the new agency, this would benefit $£ 21$ million. 
An additional scenario analysis was carried out for the probability of an outbreak of disease $i$ being minor $\left(P_{i, \text { Minor }}\right)$ to see the effect of an improved outbreak response initiative on the mean expected total cost of disease outbreaks without financial benefits from setting up the new agency (Figure 5). For all of the diseases, except for UMD (for which by definition $P_{i, \text { Minor }}=$ $0), P_{i, \text { Minor }}$ was increased from its baseline value given in Table 1 . From this analysis it is predicted that an improved outbreak response for AI and BT, in particular, could greatly reduce the costs of animal disease outbreak. The model is more sensitive to these two diseases because they are predicted to occur most frequently (i.e., two AI outbreaks per year and one BT outbreak every 2 years).

A tornado chart for the sensitivity analysis is shown in Figure 6. This shows that the total estimated cost of animal disease outbreaks over the 30 years was highly sensitive to the potential for an outbreak of a UMD. The other influential diseases were BT, FMD, and AI.

\section{DISCUSSION}

The use of a stochastic model enhances the RP method for dealing with the uncertainties regarding the proposed new agency for animal health in England. The RP approach assumes constant risk levels and factors over a decision period. When presenting the potential cost of future exotic disease outbreaks, Defra (2009b) acknowledge that the figures are not forecasts or predictions of what will, or is likely to, happen. Rather they illustrate the possible scale of outbreak costs and illustrate what might be achieved by reducing those costs. Animal disease spread changes in nature. Unknown animal diseases may emerge (e.g., Bovine Spongiform Encephalopathy), or new disease may appear through intrusion (e.g., African Horse Sickness) or environmental change (e.g., Bluetongue). While the stochastic model developed here incorporated RP, it also enabled observation of the probability of one or more outbreaks occurring within a specified time period. The stochastic approach therefore has a higher resolution than RP alone for assessing the impact of the new agency (Barbolini et al. 2003). Compared to any deterministic approach, it provides additional information on the possible number of outbreaks and costs by providing $5^{\text {th }}$ and $95^{\text {th }}$ percentiles (Galson Sciences Limited 2001). However, it is important to note the inherent assumptions within this stochastic model. For example, over a 30-year period, the predicted frequency of the different outbreaks is likely to change dependent on the worldwide animal disease situation. Such changes would be potentially 
significant and it is therefore important that these data for the "chance of outbreak" are reviewed on a regular basis to assess if still realistic. Likewise the probability of a minor or major outbreak may change over time, dependent on outbreak control measures and livestock industry structures (e.g., animal movements). However, the scenario analysis carried out for $P_{i, \text { Minor }}$ indicates the total cost of the agency would only be significantly affected by changes in $P_{i, \text { Minor }}$ for AI and BT. It is estimated that the establishment of the new agency would be a viable investment. Even at the benefit rate of $0.5 \%$, with the expected cost of disease outbreaks over the 30 years totalling $£ 4118$ million $(1925,8440)$, and after the set-up and annual running costs are accounted for ( $£ 14.3$ million and $£ 2.7$ million, respectively), the new agency would benefit $£ 21$ million (Figure 4). Likewise, if the new agency could achieve a reduction of $2 \%$ in the cost of animal disease outbreaks over 30 years (Scenario B), there would be a benefit of $£ 80$ million. However, the potential benefits calculated based on the estimated costs of animal disease outbreaks were highly sensitive to the potential for an outbreak of unknown major disease (UMD). According to Defra's historical data (Defra 2009b), an outbreak of UMD has been in the past a highly unlikely event ( 1 in 100 years). Although if realised a UMD is estimated to cause very high costs that are similar in scale to the Bovine Spongiform Encephalopathy (BSE) outbreak in the UK during the 1980s/early 1990s, i.e., £5 billion.

Decision-making is complex and dynamic, particularly with regard to animal diseases. Qualitative factors such as technological (e.g., new vaccines), political (e.g., changing regulation on vaccination), and social considerations (e.g., cultures that may obstruct investment options) should also be considered (Khan 2008; Nowak 2005). In addition, the most economically (quantitatively) viable decision may not necessarily be favoured by Governments. Our future work will be focusing on stochastic processes including non-homogenous Poisson processes, Cox processes and mixed processes to model the occurrences of disease outbreaks. When costs associated with the occurrences of disease outbreaks are considered, marked Poisson processes models are suggested.

\section{CONCLUSION}

This paper explored the applicability of a stochastic model to enhance the RP approach to animal disease risk assessment. The static nature of the RP approach limits its applicability for projecting the variability of the number of outbreaks over the lifespan of the proposed new 
agency for animal health in England. However, taking a stochastic approach this variability can be incorporated. The results from the stochastic model show that the average total cost of the new agency (including outbreak, set-up and running costs) is $£ 4118$ million with $£ 1925$ million and $£ 8440$ million as the $90 \%$ certainty interval. The large variability associated with the cost is attributable to the possibility of an UMD outbreak, although BT, FMD, and AI were also influential on the potential costs for the new agency. The results from the stochastic model also show that the new agency is likely to be a viable investment even with only a $0.5 \%$ reduction in disease costs, which could potentially save $£ 21$ million. The stochastic approach offers Defra an enhanced approach to the RP method for dealing with the uncertainties in any continuing deliberations regarding the proposed new agency.

\section{ACKNOWLEDGEMENTS}

This work has benefited from close cooperation with Defra and its agencies. We especially thank Edgar Black, David Mouat and Allick Simmons for their inputs. The study was supported by the Animal Health and Veterinary Laboratories Agency, Defra and a cross-Council (EPSRC, NERC, ESRC) research grant (EP/G022682/1) awarded to Cranfield University.

\section{REFERENCES}

Anderson I. 2002. Inquiry into the Lessons to be Learned from the Foot and Mouth Disease Outbreak of 2001. The Stationery Office, London, UK

Anderson I. 2008. Foot and Mouth Disease 2007: A Review and Lessons Learned. The Stationery Office, London, UK

Barbolini M, Capabiancca F, and Savi F. 2003. A new method for the estimation of avalanche distance exceeded probabilities. Surveys in Geophysics 24:587-601

BERR (Department for Business Enterprise and Regulatory Reform). 2007. Statutory Code of Practice for Regulators. Department for Business Enterprise and Regulatory Reform, London, UK

Charles KJ and Ashbolt NJ. 2004. Quantitative microbial risk assessment: A catchment management tool to delineate setback distances for septic systems, In: Lens P and Stuetz R (eds), Young Researchers. Water and Environment Management Series, pp 139-46. IWA publishing, London, UK 
Defra (Department for Environment, Food and Rural Affairs). 2000. Flood and Coastal Defence Project Appraisal Guidance: Approaches to Risk. Available at http://www.defra.gov.uk/Environ/Fcd/pubs/pagn/fcdpag4.pdf

Defra 2009a. Consultation on a New Independent Body for Animal Health. Available at http://www.defra.gov.uk/corporate/consult/new-independent-body-ah/consultation-document.pdf

Defra. 2009b. Impact Assessment of an Independent Body for Animal Health in England. Available at http://www.defra.gov.uk/corporate/consult/new-independent-body-ah/impact-assessment.pdf. Last accessed $02 / 06 / 2009$

Fraile R, Berthet C, Dessens J, et al. 2003. Return periods of severe hailfalls computed from hailpad data. Atmospheric Res 67:189-202

Galson Sciences Limited. 2001. Presenting Numerical Risk Estimates. Environment Agency, Bristol, UK

Gaythwaite J. 2004. Design of Marine Facilities for the Berthing, Mooring, and Repair Vessels. American Society of Civil Engineers, Reston, VA, USA

Gosling JP, Hart A, Mouat DC, et al. 2011. Quantifying experts' uncertainty about the future cost of exotic diseases. Risk Analysis 32: 881-93

IRMA (Institute for Risk Management and Agriculture). 2003. A Risk Financing Model for Livestock Epidemics in the European Union. Available at

http://ec.europa.eu/food/animal/diseases/financial/risk_financing_model_10-04_en.pdf

Khan AM. 2008. Sustainability criteria for the evaluation of urban transportation systems. Proceedings of the Annual Conference of the Canadian Society for Civil Engineering 4:2693-702

Mays LW. 2005. Water Resources Engineering. John Willey \& Sons, New York, NY, USA

McClung DM. 1999. The encounter probability for mountain slope hazards. Canadian Geotechnical J 36:1195-6

Mintz JM. 1990. Corporate tax holidays and investment. World Bank Economic Rev 4:91-102

Monsour AE and Preston DB. 1995. Return periods and encounter probabilities. Applied Ocean Res 17:127-36

Niemi JK and Lehtonen H. 2011. Modelling pig sector dynamic adjustment to livestock epidemics with stochasticduration trade disruptions. European Rev Agricul Econ 38:529-51

Nowak M. 2005. Investment projects evaluation by simulation and multiple criteria decision aiding procedure. $\mathbf{J}$ Civil Engineer Manage 11:193-202 
Ozger M and Sen Z. 2008. Return period and risk calculations for ocean wave energy applications. Ocean Engineer $35: 1700-6$

Petrucci O, Polemio M, and Pasqua AA. 2009. Analysis of damaging hydrological events: The case of the Calabria region (Southern Italy). Environ Manage 43:483-95

Pratt SP, Relly RF, and Schweihs RP. 2000. Valuing a Business the Analysis and Appraisal of Closely Held Companies. McGraw Hill, New York, NY, USA

Ranjan R and Lubowski R. 2005. A model of producer incentives for livestock disease management. Stochastic Environ Res Risk Assess 19:315-25

Sullivan W, Wicks E, and Luxhoi J. 2006. Engineering Economy. Prentice Hall, New York, NY, USA

Vose D. 2008. Risk Analysis. John Wiley \& Sons, Chichester, UK.

Williams MS, Ebel ED, and Wells SJ. 2009. Poisson sampling: A sampling strategy for concurrently establishing freedom from disease and estimating population characteristics. Preventative Vet Med 89:34-42 
Table 1. Potential occurrence and costs of minor and major outbreaks (Defra 2009b). The $y_{i}$ and $c_{i, m a j o r}$ of "unknown major disease" were determined by Defra (2009b) based on their historical data of outbreaks that are, for example, similar in scale to the BSE outbreak in the UK during the 1980s/early 1990s, and have been in the past highly unlikely event (1\% risk in any year) but if it should arise it would cause very high costs (e.g., $£ 5$ billion - similar in scale to BSE). The very high cost of such an event leads to the high "expected annual cost".

\begin{tabular}{|c|c|c|c|c|c|c|c|}
\hline \multirow[t]{2}{*}{ Disease } & \multirow[t]{2}{*}{$\begin{array}{l}\text { Disease } \\
\text { indicator } \\
(i)\end{array}$} & \multirow[t]{2}{*}{$\begin{array}{l}\text { Main } \\
\text { species } \\
\text { affected }\end{array}$} & \multirow{2}{*}{$\begin{array}{l}\text { Chance of } \\
\text { outbreak } \\
\text { once every } \\
\text { "how many } \\
\text { years" }\left(y_{i}\right)\end{array}$} & \multicolumn{2}{|c|}{$\begin{array}{l}\text { Probability that } \\
\text { outbreak is }\end{array}$} & \multicolumn{2}{|c|}{$\begin{array}{c}\text { Incident cost } £ M \text { if } \\
\text { outbreak is }\end{array}$} \\
\hline & & & & $\begin{array}{l}\text { Minor } \\
\boldsymbol{P}_{i, \text { Minor }}\end{array}$ & $\begin{array}{l}\text { Major } \\
P_{i, \text { Major }}\end{array}$ & $\begin{array}{l}\text { Minor } \\
c_{i, \text { Minor }}\end{array}$ & $\begin{array}{l}\text { Major } \\
c_{i, \text { Major }}\end{array}$ \\
\hline $\begin{array}{l}\text { Avian Influenza } \\
\text { (AI) }\end{array}$ & 1 & Poultry & 0.5 & 0.9 & 0.1 & 5 & 60 \\
\hline $\begin{array}{l}\text { Bluetongue } \\
\text { (BT) }\end{array}$ & 2 & $\begin{array}{l}\text { Cattle, goats, } \\
\text { sheep }\end{array}$ & 2 & 0.9 & 0.1 & 70 & 200 \\
\hline $\begin{array}{l}\text { Newcastle Disease } \\
\text { (ND) }\end{array}$ & 3 & Poultry & 3 & 0.95 & 0.05 & 5 & 60 \\
\hline $\begin{array}{l}\text { Classical Swine } \\
\text { Fever (CSF) }\end{array}$ & 4 & Pigs & 8 & 0.7 & 0.3 & 10 & 90 \\
\hline $\begin{array}{l}\text { Foot and Mouth } \\
\text { Disease (FMD) }\end{array}$ & 5 & $\begin{array}{l}\text { Cattle, goats, } \\
\text { sheep }\end{array}$ & 15 & 0.9 & 0.1 & 100 & 500 \\
\hline $\begin{array}{l}\text { African Swine Fever } \\
\text { (ASF) }\end{array}$ & 6 & Pigs & 12 & 0.7 & 0.3 & 15 & 120 \\
\hline $\begin{array}{l}\text { Swine Vesicular } \\
\text { Disease (SVD) }\end{array}$ & 7 & Pigs & 20 & 0.95 & 0.05 & 5 & 50 \\
\hline $\begin{array}{l}\text { Unknown major } \\
\text { disease (UMD) }\end{array}$ & 8 & Unknown & 100 & 0 & 1 & - & 5000 \\
\hline $\begin{array}{l}\text { Other known } \\
\text { notifiable not listed } \\
\text { above (OKN) }\end{array}$ & 9 & Various & 8 & 0.7 & 0.3 & 5 & 20 \\
\hline
\end{tabular}




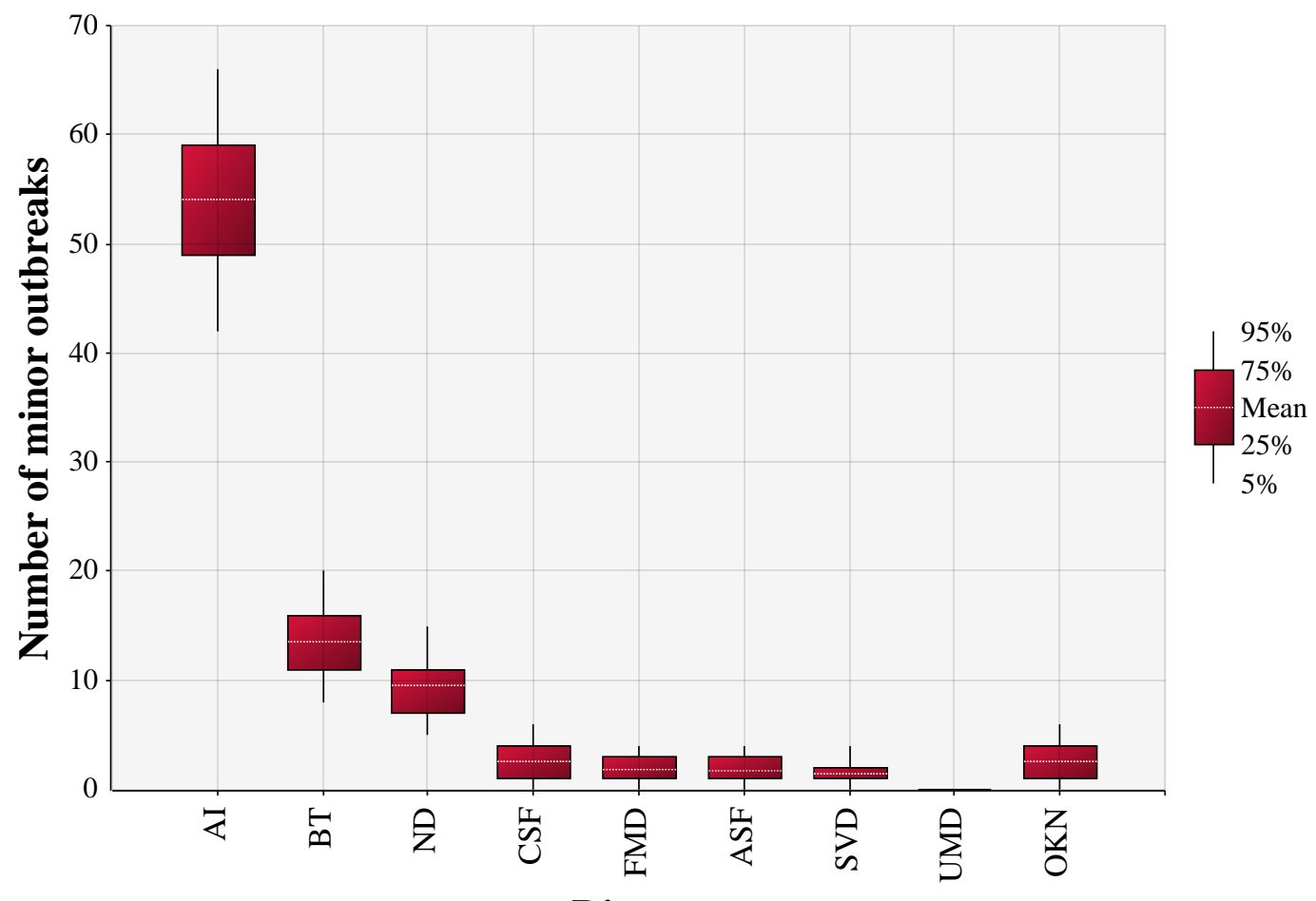

Disease

Figure 1. Box-plot for the estimated number of minor outbreaks over a 30 -year period $\left(O_{i, \text { Minor }}\right)$.

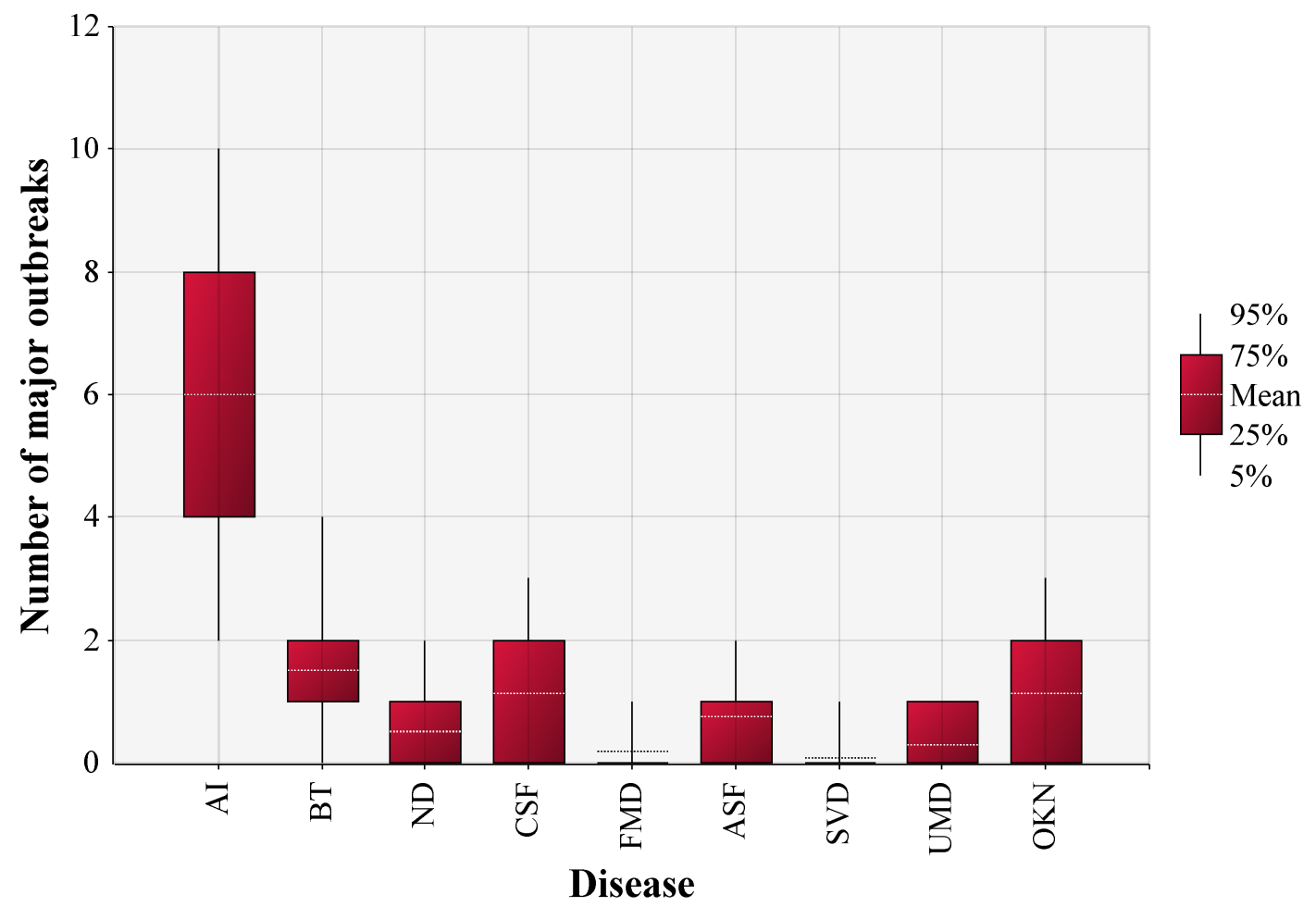

Figure 2. Box-plot for the estimated number of major outbreaks $\left(O_{i, \text { Major }}\right)$. 


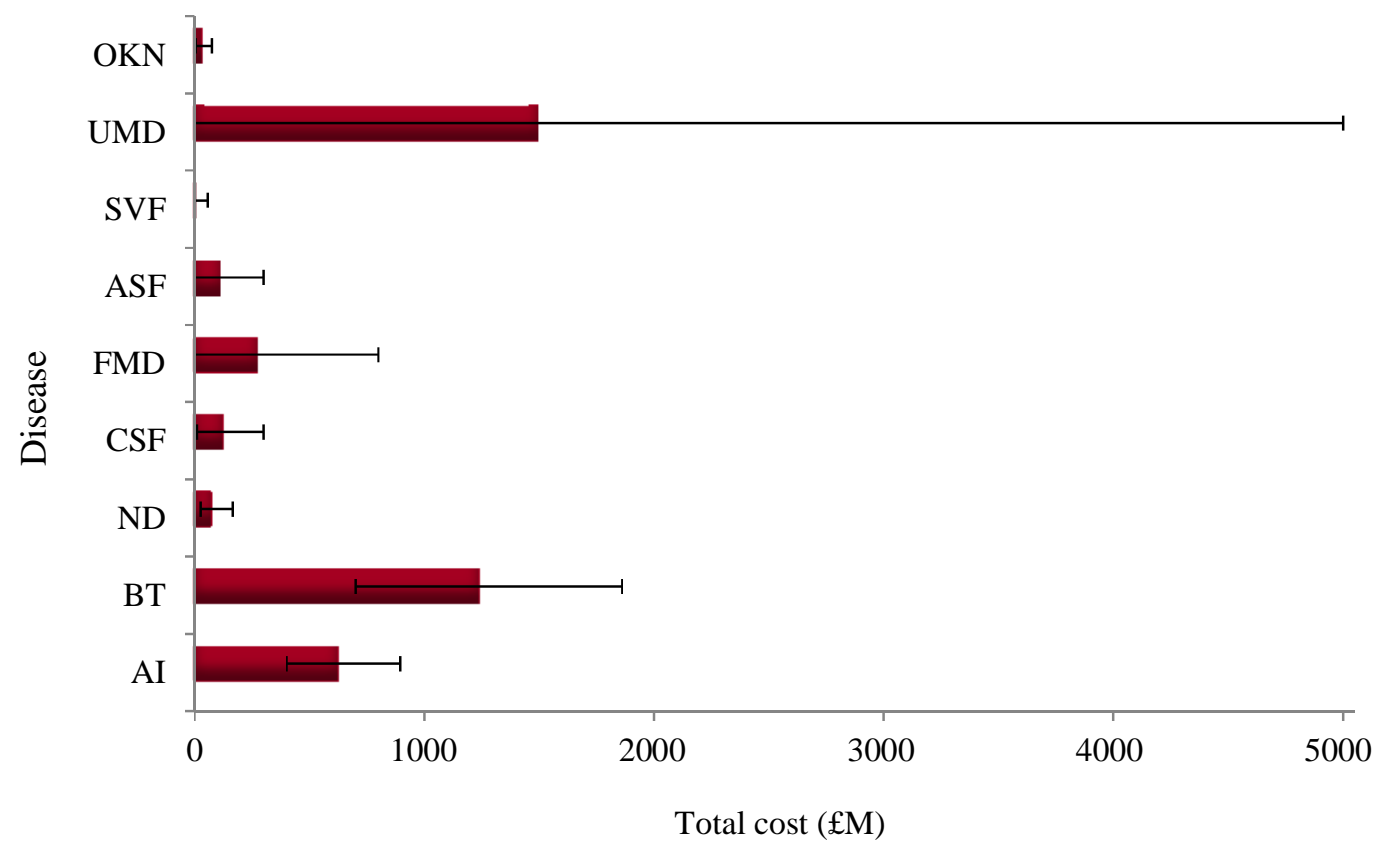

Figure 3. Estimated costs mean, $5^{\text {th }}$ percentile and $95^{\text {th }}$ percentile of minor and major outbreaks in a 30 -year period.

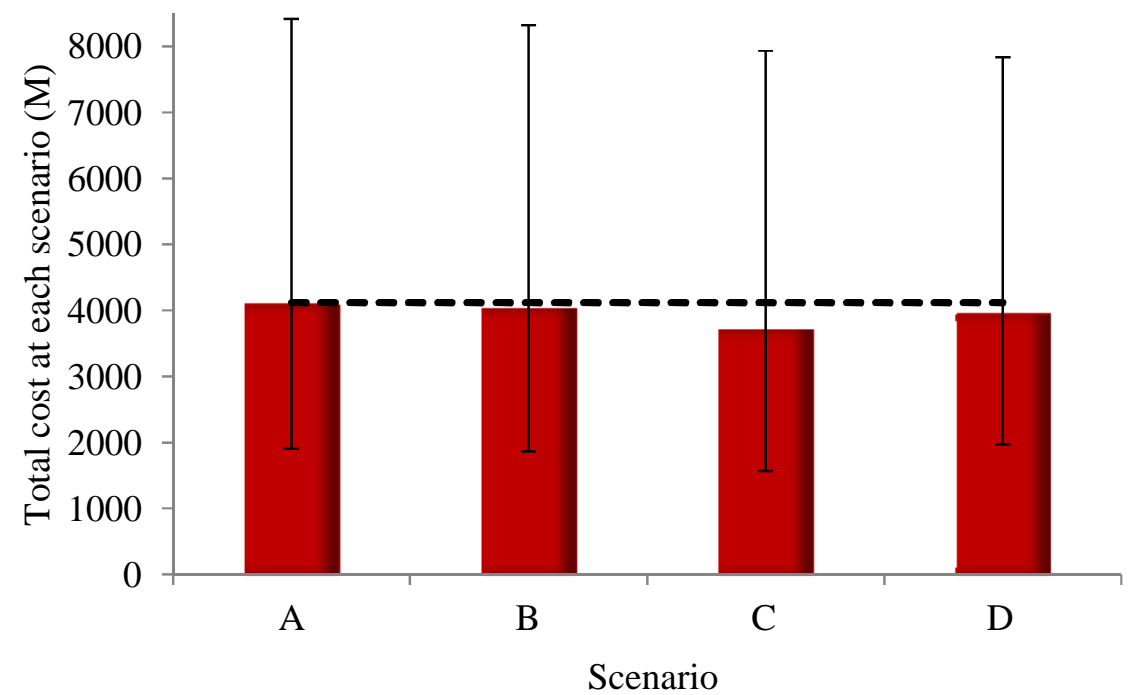

Figure 4. Total costs of animal disease outbreak reduced accordingly for each scenario over 30 years. $\mathrm{A}=0.5 \%$ benefit, $\mathrm{B}=2 \%$ benefit, $\mathrm{C}=10 \%$ benefit, and $\mathrm{D}=0.5 \%, 2 \%$, and $10 \%$ benefit for years 1-10, 11-20, and 21-30, respectively. The dashed line denotes the estimated average total cost of animal disease outbreak without any financial benefits from setting up the new agency (i.e., £4118 million). 


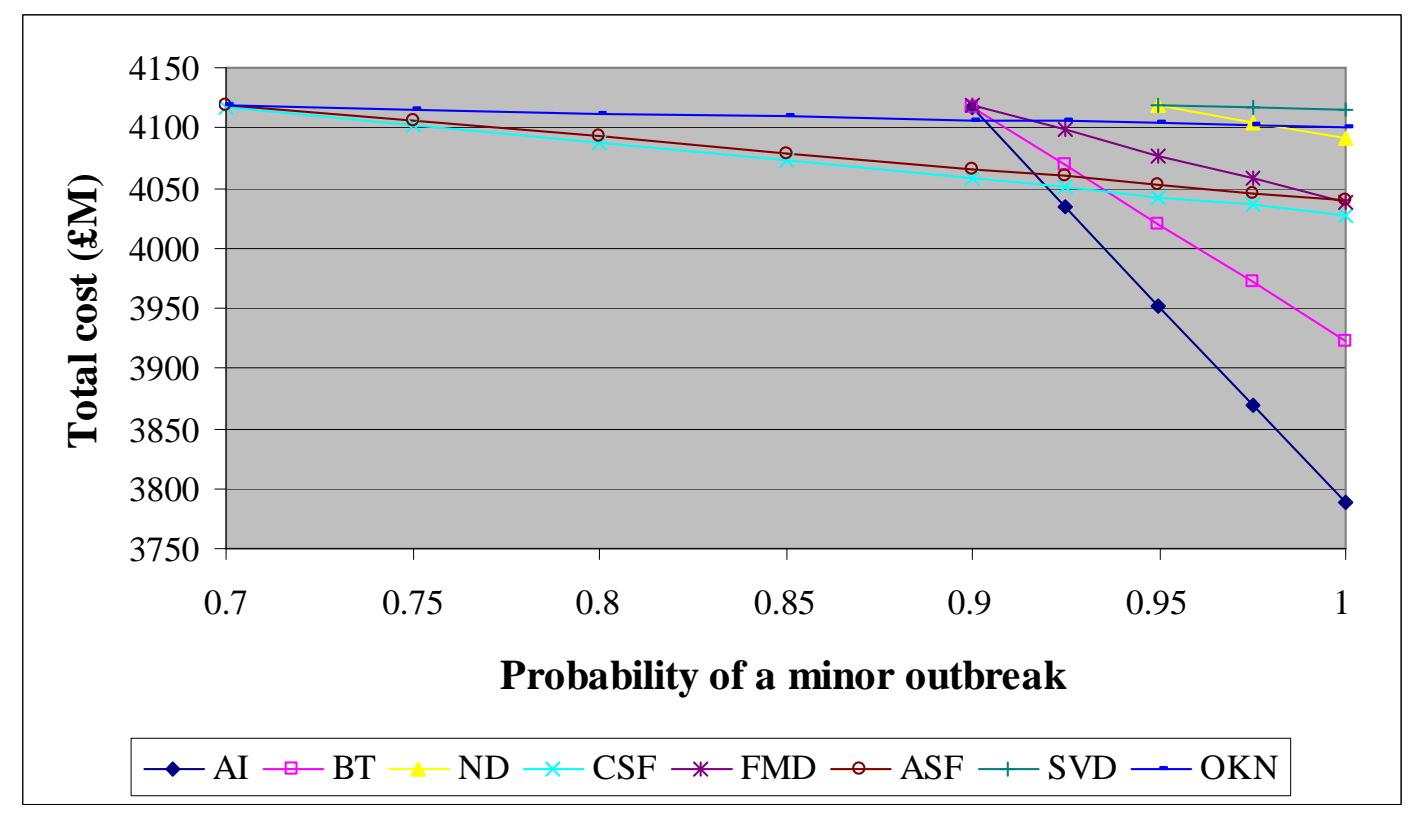

Figure 5. A scenario analysis for the probability of an outbreak of disease $i$ being minor $\left(P_{i, \text { Minor }}\right)$ showing the effect of an improved outbreak response initiative on the mean expected total cost of disease outbreaks without financial benefits from setting up the new agency.

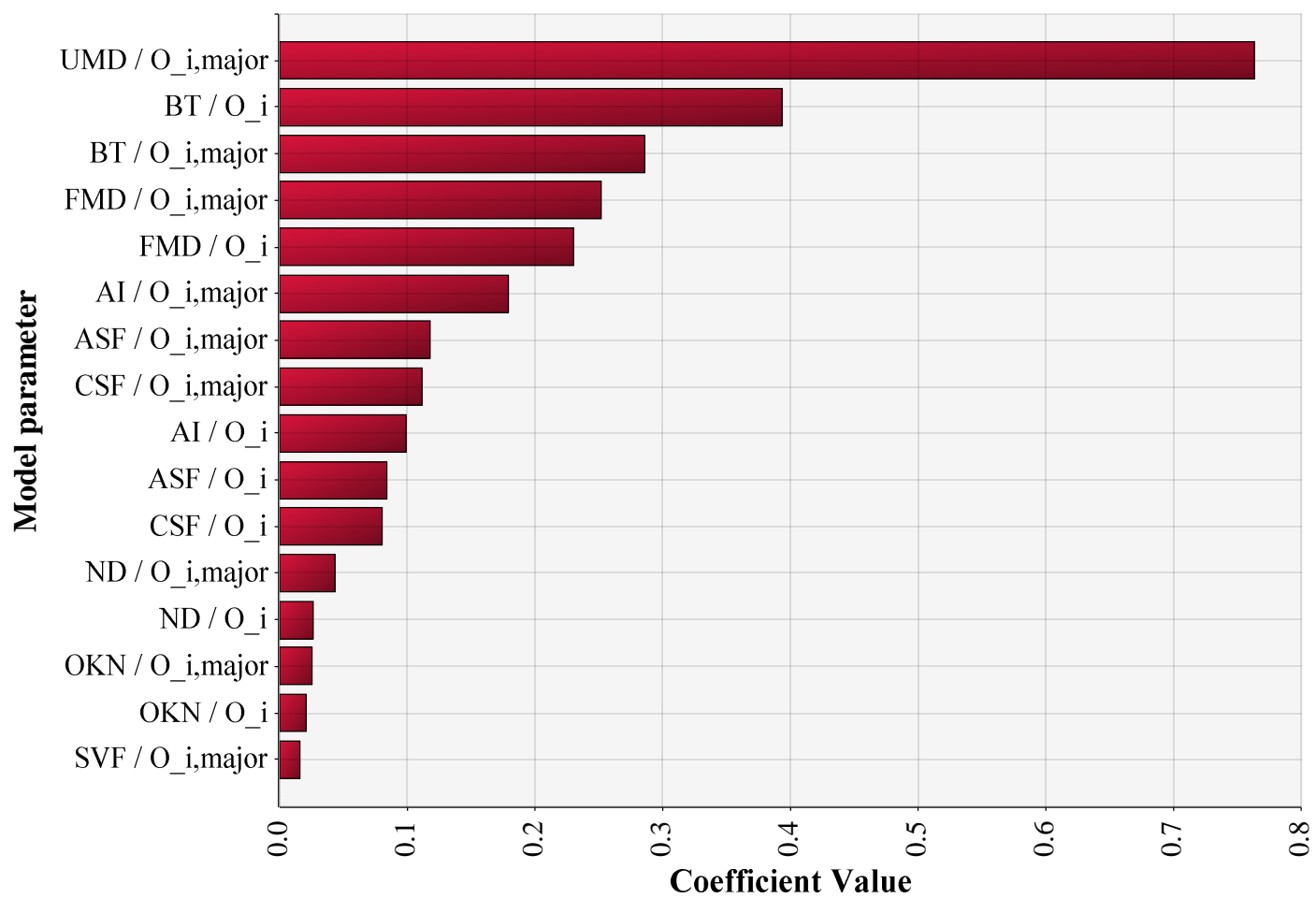

Figure 6. Sensitivity analysis to assess the relative importance of the variables on the total costs of animal disease outbreaks over a 30 -year period. 